\title{
Assessment of men involvement in family planning services use and associated factors in rural Ghana
}

Senanu Abigail Kpekpo Kwawukume ${ }^{1}$, Alexander Suuk Laar ${ }^{2 *}$ and Tanko Abdulai ${ }^{3}$

\begin{abstract}
Background: In low-and-middle income countries (LMICS) less attention is paid to men's involvement in Family Planning (FP) programs where public health officials have advocated the involvement of men as a strategy for addressing the dismal performance of FP programs. The study assessed the involvement of men in FP use and the factors which promote or hinder the uptake of FP services among partners in a rural setting of northern Ghana.
\end{abstract}

Methods: A cross-sectional descriptive study was used to collect data from 200 respondents. Study respondents were selected through random cluster sampling.

Results: The findings showed that male partners' knowledge (95.5\%) and approval (72.8\%) of FP services were high. About 48\% of men were involved in FP service utilization. Having living children $(a \mathrm{OO} ; 1.71(1.27,2.15))$ and being knowledgeable (aOR; $6.14(1.38,10.90))$ about FP were positively associated men's involvement in FP service utilization. The findings also indicated that men had a higher propensity $\left(X^{2}=4.5534, p=0.033\right)$ of supporting a FP method use. Women who reported that their spouse supported FP method use were more likely to use a contraceptive method $\left(X^{2}=9.5223, P=0.002\right)$ if their spouse supported FP method use $(X 2=9.5223, P=0.002)$ and if their partners had some education $(X 2=14.1133, P=0.000)$. Reasons for low contraceptive use were health risks, side effects, and sociocultural norms.

Conclusion: Family planning programs need to include men at all levels of health promotion and education of FP programs to help reduce misconceptions about contraceptive methods to increase acceptance and use among partners in rural settings of Ghana.

Keywords: Family planning services, Men, Partners, Upper west region, Ghana

\section{Background}

Worldwide, $12 \%$ of married or in-union women are estimated to have had unmet need for contraceptive methods [1]. In LMICs, 214 million women of reproductive age who want to avoid pregnancy are not using modern contraceptive method [1]. In Sub-Saharan Africa, the proportion of women who have an unmet

*Correspondence: laar.alex.suuk@gmail.com

${ }^{2}$ REJ Institute, Research and ICT Consultancy Services, Tamale, Northern Region, Ghana

Full list of author information is available at the end of the article need for modern contraception is highest at $21 \%$ [1]. Unmet need for modern contraception and family planning (FP) accounts for $80 \%$ of unintended pregnancy in LMICs [1]. In Ghana, the contraceptive prevalence rate among all women aged $15-49$ years is $25 \%$, with $20 \%$ using modern methods [2] with a high unmet need of 45.7\% [3]. Contraceptive use interventions and unmet need for FP are important determinants of fertility decline in LMICs [4]. Promotion of FP and ensuring access to preferred contraceptive methods for women and couples is essential to securing the well-being and autonomy of women [1]. Men participation in FP can be original author(s) and the source, provide a link to the Creative Commons licence, and indicate if changes were made. The images or other third party material in this article are included in the article's Creative Commons licence, unless indicated otherwise in a credit line to the material. If material is not included in the article's Creative Commons licence and your intended use is not permitted by statutory regulation or exceeds the permitted use, you will need to obtain permission directly from the copyright holder. To view a copy of this licence, visit http://creativecommons.org/licenses/by/4.0/. The Creative Commons Public Domain Dedication waiver (http://creativeco mmons.org/publicdomain/zero/1.0/) applies to the data made available in this article, unless otherwise stated in a credit line to the data. 
either as a user of male contraceptive methods and or encouraging and supporting their partners or wives in contraception [5]. Family planning services are critical to improving maternal and child health and reducing maternal and infant mortality in LMICs [6]. Expanding FP services and involving men in LMICs such as Ghana could increase utilization of services in this setting could avert up to $42 \%$ of maternal deaths $[6,7]$.

Men are also recognized to be responsible for the large proportion of reproductive ill-health suffered by their partners' use of FP methods [8]. Although contraceptive methods and services are frequently geared towards women, men are often the primary decision-makers on family size and their partners' use of FP methods [9]. It is well documented that men's general knowledge and attitude about the ideal family size, gender preference of children, ideal spacing between childbirths, and contraceptive methods use greatly influence women's preferences and opinions $[8,10,11]$.

In Ghana, the focus of this study, knowledge of any contraceptive method is almost universal, with 98\% of all women and $99 \%$ of all men knowing at least one method of contraception and where $50 \%$ of all women reported having used a method of contraception before [12]. According to the Ghana Demographic and Health Survey (2014), only $27 \%$ of married women use FP with $22 \%$ using a modern method and 5\% using the traditional method [13]. Family planning programs in Ghana dates as far back as 1956 [14], however, uptake of FP services has not been encouraging and even worst in rural Ghana including the Sissala East District in Tumu of the Upper West Region where utilization of PF decreased from $71.4 \%$ in 2011 to $50.7 \%$ in 2012 [15]. In Ghana, The male partner may have an influence in decision-making regarding contraceptive use and the number of offspring they would like to have. Family planning research in rural Upper West Region has been dominated by findings almost exclusively from women studies.

Men in rural Ghana are seen to be the head of the home and influence the healthcare decisions of the entire household affairs [16]. Studies have also shown an increase in contraceptive use in cases where men partners have been involved $[9,17]$. Men's involvement helps not only in accepting contraceptives uptake but also its effective use and continuation $[9,10,17]$. However, male partners' role in FP services promotion and uptake has often been overlooked and neglected in rural areas in Africa such as Ghana. To fill this research gap, this study assessed the involvement of men in FP service utilization and the factors that determine their involvement in contraceptive uptake among women in a rural district of the Upper West Region.

\section{Method}

\section{Study setting}

The study took place in Tumu in the Sissala East District in the north-eastern part of the Upper West Region of Ghana. Tumu, the district capital is predominantly rural by nature, with the majority (85\%) living in rural settings $[18,19]$. A large percentage $(84 \%)$ of the population lives below the poverty line $[18,19]$. A greater proportion $(76 \%)$ of the population are being engaged in agriculture. It is predominantly Islam (88.0\%) with Christianity being the largest of the minority (10\%) followed by Traditional $(1.4 \%)[18,19]$. A greater proportion of the population (52.4\%) has Some level of education [18].

\section{Study design}

A cross-sectional descriptive study design was used for this study. An interviewer-administered questionnaire consisting of both open and close-ended questions was administered by experienced research assistants to elicit the necessary information from the study population.

\section{Sampling technique and sample size}

The sample size for this study was determined using the Yamane method: Sample Size $=\frac{\mathrm{N}}{1+\mathrm{N}(\mathrm{p})^{2}}$ where $N=$ Total Population, $p=$ margin of error (5\%). A sample size of 386 was derived from the total population of 11,252.

\section{Study population}

The study population consisted of adult males and females aged 15 years and above who were either married or cohabitating. For this study, we aimed at recruiting 386 respondents but finally recruited 200 respondents due to logistical constraints.

\section{Data collection method}

An interviewer-administered questionnaire consisting of both closed and open-ended questions was used to assess the knowledge and use of FP services among partners and the level of involvement of male partners in FP service utilization. The study questionnaire was developed based on the objective of this study by the principal investigator. The questionnaire was administered by the first author and two experienced research assistants who understand the native dialect. The questionnaire was translated into the local dialect and administered by the two research assistants for participants who could not understand or speak the English language. The questionnaire was administered among households in five communities or clusters out of the ten in Tumu municipality. These communities were chosen using a simple random sampling method. Forty respondents were interviewed from each community. This method gave the individual an equal chance of being selected. Before consent 
was sought from respondents, the aim of the study was explained to each individual. They were also assured of confidentiality and privacy of the information they will give. The questionnaires were pretested in a similar environment in the district.

\section{Outcome variable}

Male participants were asked whether they approved and/or encourage use FP of their partners, ever discussed FP with their partners, provided material support to their partners to access FP services and whether they have used FP themselves in the past. Responses to these questions were them summed to give the level of male partners' involvement in FP utilization (with no weight given to these variables); the highest possible involvement score was five (indicating a high level of involvement), a zero score indicated no involvement in FP utilization, and score of 3 was considered as sufficient involvement. The involvement of men in FP service utilization for themselves and/or their partners was the main outcome of the study. Female respondents were also asked; if they discuss FP with their male partners, gets approval to use FP from their male partners and whether they receive support from their male partners to access FP services.

\section{Covariates}

The demographic characteristics (age, education, occupation, and religion) and knowledge about FP were the covariates considered for our analyses.

\section{Data management and analysis}

To ensure accuracy, the data collected was checked and screened for completeness. The completed copies of the questionnaire were serially numbered and doubly entered and analyzed using Statistical Package for Social Scientists version 20.0. Bivariate and regression analyses were used to determine the associations between the outcome variables and a host of explanatory variables.

\section{Results}

\section{Background characteristics of respondents}

Two hundred (200) respondents were interviewed for this study. The study involved 107 men representing $53.5 \%$ and 93 women representing 46.6\%. Respondents' age ranged between 15 and 54 for men and 15-49 for women. In all, over $70 \%$ (76.5\%) had some form of education ranging from primary to tertiary while $23.5 \%$ had no education (Table 1 ). All the respondents were involved in some kind of work with over $60 \%$ (66\%) being artisans.

\section{Knowledge of family planning}

Majority of the male respondents (95.5\%) had heard of FP. Almost half of the respondents (48.1\%) had information about FP via the mass media (Television, Radio, and Newspaper) followed by friends (27.5\%) and the health facility (23.5\%) as indicated in Table 2.

Twenty eight percent $(28.0 \%)$ of the men interviewed understood FP as avoidance of unintended pregnancy, $25.2 \%$ as limiting family size while $19.6 \%$ understood it as spacing of childbirth. Others (27.1\%) explained it as two or more of the above definitions as shown in Table 3. The most common method known and used was the condom (42.5\%) followed by implants (32.0\%) and the least known method being the foaming tablet $(7.0 \%)$ among male respondents.

\section{Men involvement in FP}

Over $50 \%$ (52.2\%) of the male respondents reported they or their partner were currently using some form of contraceptives to delay or avoid pregnancy. However, only $36.4 \%$ of women reported they or their partners were currently using contraceptives to delay or avoid pregnancy. The majority of the men respondents (72.8\%) approved of the use of FP methods by their partners, 75\% of the women respondents also indicated their partners had approved of their use of FP. The findings also indicate that men had a higher propensity of reporting FP use $\left(\mathrm{X}^{2}=4.5534, p=0.033\right)$. For the couples who did not approve of the FP methods, the reasons included: sociocultural beliefs (31\%), side effects (30.8\%) such as delayed or absence of menses, and difficulty of conceiving after terminating use of FP and others (38.5\%).

Overall, about $48 \%$ of men were sufficiently involved in FP service utilization (see Table 1). Involvement of men in FP use was positively associated with knowledge of FP and the number of living children (Table 4).

\section{Decision making in FP use}

We wanted to know from the women whether their partners support them in their desire to use contraceptives; $67.0 \%$ of the women answered in the affirmative and $33.0 \%$ answered in a negative. Those who answered in the affirmative said their partners support them by providing money for transport to facility and/or for FP services, encouraging and accompanying them to the health facility. Women who reported that their spouse support FP use were more likely to use a contraceptive method $\left(\mathrm{X}^{2}=9.5223, P=0.002\right)$ compared to those who said no. Women who reported their partners had some education were also more likely to use a contraceptive method $\left(\mathrm{X}^{2}=14.1133, P=0.000\right)$. In all, female respondents tended to report more favorable attributes for their male partners' involvement than the male respondents (Fig. 1).

Generally, a greater proportion of men $(77.6 \%)$ intend using FP in the future. For those who answered in a negative, $19.1 \%$ said most of the contraceptives were designed 
Table 1 Background characteristics of participants

\begin{tabular}{|c|c|c|c|c|}
\hline & \multicolumn{2}{|c|}{ Male $(n=107)$} & \multicolumn{2}{|c|}{ Female $(n=93)$} \\
\hline & Frequency & Percent (\%) & Frequency & Percent (\%) \\
\hline \multicolumn{5}{|l|}{ Age } \\
\hline $15-24$ & 25 & 23.36 & 47 & 50.54 \\
\hline $25-34$ & 40 & 37.38 & 19 & 20.43 \\
\hline $35-44$ & 19 & 17.76 & 19 & 20.43 \\
\hline $45-54$ & 8 & 7.48 & 8 & 8.60 \\
\hline $55+$ & 15 & 14.02 & & \\
\hline \multicolumn{5}{|l|}{ Marital Status } \\
\hline Single & 43 & 40.57 & 36 & 38.71 \\
\hline Married & 56 & 52.83 & 52 & 55.92 \\
\hline Cohabiting & 6 & 5.66 & 3 & 3.23 \\
\hline Divorced/widowed & 1 & 0.94 & & \\
\hline \multicolumn{5}{|c|}{ Number years in current relation } \\
\hline$<5$ years & 44 & 52.38 & 56 & 66.67 \\
\hline $5-9$ years & 15 & 17.86 & 9 & 10.71 \\
\hline $10+$ years & 25 & 29.77 & 19 & 22.62 \\
\hline \multicolumn{5}{|l|}{ Education } \\
\hline None & 17 & 15.89 & 30 & 32.26 \\
\hline Primary & 5 & 4.67 & 7 & 7.53 \\
\hline Junior High School & 16 & 14.95 & 19 & 20.43 \\
\hline High School & 26 & 24.30 & 27 & 29.03 \\
\hline Tertiary & 43 & 40.19 & 10 & 10.75 \\
\hline \multicolumn{5}{|l|}{ Occupation } \\
\hline Farming & 7 & 8.24 & 16 & 17.20 \\
\hline Trading & 22 & 25.88 & 22 & 23.66 \\
\hline Teachings & 16 & 18.82 & 3 & 3.23 \\
\hline Health worker & 6 & 7.06 & 5 & 5.38 \\
\hline Others & 34 & 40.00 & 47 & 50.54 \\
\hline \multicolumn{5}{|l|}{ Religion } \\
\hline Christianity & 41 & 38.32 & 24 & 25.81 \\
\hline Islam & 63 & 58.88 & 69 & 74.19 \\
\hline Traditional & 2 & 1.87 & & \\
\hline Other & 1 & 0.93 & & \\
\hline \multicolumn{5}{|l|}{ Number of living children } \\
\hline 0 & 54 & 50.46 & 36 & 38.71 \\
\hline 1 & 15 & 14.02 & 20 & 21.51 \\
\hline 2 & 11 & 10.28 & 16 & 17.20 \\
\hline 3 & 10 & 9.35 & 10 & 10.75 \\
\hline 4 & 10 & 9.35 & 5 & 5.38 \\
\hline 5 & 4 & 3.74 & 4 & 4.30 \\
\hline$>5$ & 3 & 2.80 & 2 & 2.15 \\
\hline \multicolumn{5}{|l|}{ Desired number of children } \\
\hline 1 & 2 & 1.87 & 1 & 1.08 \\
\hline 3 & 31 & 28.97 & 21 & 22.58 \\
\hline 4 & 32 & 29.91 & 31 & 33.33 \\
\hline 5 & 11 & 10.28 & 15 & 16.13 \\
\hline$>5$ & 17 & 15.89 & 11 & 11.83 \\
\hline Whatever God gives & 9 & 8.41 & 9 & 9.68 \\
\hline
\end{tabular}


Table 1 (continued)

\begin{tabular}{|c|c|c|c|c|}
\hline & \multicolumn{2}{|c|}{ Male $(n=107)$} & \multicolumn{2}{|c|}{ Female $(n=93)$} \\
\hline & Frequency & Percent (\%) & Frequency & Percent (\%) \\
\hline \multicolumn{5}{|l|}{ Ideal birth interval (years) } \\
\hline 1 & 1 & 0.93 & 11 & 11.83 \\
\hline 2 & 20 & 18.69 & 45 & 48.39 \\
\hline 3 & 57 & 53.27 & 3 & 3.23 \\
\hline Don't know & 29 & 27.10 & 34 & 36.56 \\
\hline Knowledge ofFP & 78 & 76.47 & 80 & 86.96 \\
\hline $\begin{array}{l}\text { Approves partner's use of FP/partner approves } \\
\text { use of FP }\end{array}$ & 75 & 72.82 & 69 & 75.00 \\
\hline UseFP & 48 & 52.17 & 32 & 36.36 \\
\hline Discusses FP with partner & 58 & 65.10 & 59 & 64.13 \\
\hline Ever asked partner to use FP & 38 & 41.76 & & \\
\hline $\begin{array}{l}\text { Provide support for partner to use FP/receives } \\
\text { support from partner }\end{array}$ & 46 & 52.27 & 59 & 67.05 \\
\hline \multicolumn{5}{|l|}{ Involvement score } \\
\hline 0 & 16 & 14.95 & & \\
\hline 1 & 22 & 20.56 & & \\
\hline 2 & 17 & 15.89 & & \\
\hline 3 & 21 & 19.63 & & \\
\hline 4 & 9 & 8.41 & & \\
\hline 5 & 22 & 20.56 & & \\
\hline Sufficient FP involvement & 52 & 48.60 & & \\
\hline
\end{tabular}

Table 2 Source of Information on family planning (male respondents)

\begin{tabular}{lll}
\hline Source & Frequency & Percent (\%) \\
\hline Television & 17 & 16.7 \\
Radio & 30 & 29.4 \\
Newspaper & 2 & 2.0 \\
Internet & 1 & 0.9 \\
Friends & 28 & 27.5 \\
Health facility & 24 & 23.5 \\
Total & $\mathbf{1 0 2}$ & $\mathbf{1 0 0 . 0}$ \\
\hline
\end{tabular}

Table 3 Men understanding of meaning of family planning

\begin{tabular}{lll}
\hline Meaning & Frequency & Percent (\%) \\
\hline Limiting family size & 27 & 25.2 \\
To avoid unintended pregnancy & 30 & 28.0 \\
Spacing childbirth & 21 & 19.6 \\
Others & 29 & 27.1 \\
Total & $\mathbf{1 0 7}$ & $\mathbf{9 9 . 9}$ \\
\hline
\end{tabular}

to suit women and thought it was a woman's business. Nearly three quarters of women (73.4\%) who ever used a FP method indicated their partner had a say in the decision to use. For the women interviewed,70.7\% said they would still practice birth control irrespective of their partners' opinion while $23.9 \%$ would not use birth control if their partners were against it, $5.4 \%$ were however not certain.

\section{Discussion}

This study assessed male partners' involvement and factors associated with the use of FP services in Tumu in the Sissala East District of the Upper West Region of Ghana. The study identified several factors that influence FP services use among male partners in this setting. Our study demonstrated that despite the high knowledge of modern contraceptive methods among couples, use was low due to perceived side effects and socio-cultural beliefs. Men's attitude and social practice towards FP methods also influence the behavior of their partners using contraceptives [20]. It is found elsewhere that the decision not to practice FP is men-dominated and men are responsible for providing contraceptive decisions when FP is practiced [21]. A major limitation facing low-andmiddle income countries FP promotion programs and 
Table 4 Determinants of male involvement in FP

\begin{tabular}{|c|c|c|c|c|}
\hline & Unadjusted OR (CI) & $P$-value & Adjusted OR (CI) & $P$-value \\
\hline Age & $1.28(0.99,1.57)$ & 0.0556 & $1.08(0.74,1.42)$ & 0.7004 \\
\hline Marital Status & $1.13(0.84,1.42)$ & 0.4215 & $0.91(0.70,1.12)$ & 0.4743 \\
\hline Number of years in relationship & $0.92(0.65,1.19)$ & 0.6479 & $0.77(0.48,1.06)$ & 0.2657 \\
\hline Education & $1.17(0.92,1.42)$ & 0.1983 & $1.19(0.95,1.43)$ & 0.1003 \\
\hline Occupation & $1.21(0.97,1.45)$ & 0.0973 & $1.28(1.00,1.56)$ & 0.0508 \\
\hline Religion & $0.57(0.13,1.01)$ & 0.0550 & $0.66(0.16,1.16)$ & 0.1432 \\
\hline \# of living children & $1.32(1.11,1.53)$ & 0.0023 & $1.71(1.27,2.15)$ & 0.0003 \\
\hline Desired \# of Children & $1.02(0.81,1.23)$ & 0.8848 & $0.93(0.71,1.15)$ & 0.5600 \\
\hline Desired birth intervals & $1.34(0.98,1.70)$ & 0.0675 & $1.30(0.95,1.65)$ & 0.0903 \\
\hline FP Knowledge & $5.81(1.24,10.38)$ & 0.0256 & $6.14(1.38,10.90)$ & 0.0179 \\
\hline
\end{tabular}

\# number, FP Family Planning. Age, education, Religion, and occupation were adjusted for

\section{FP Involvement Characteristics}

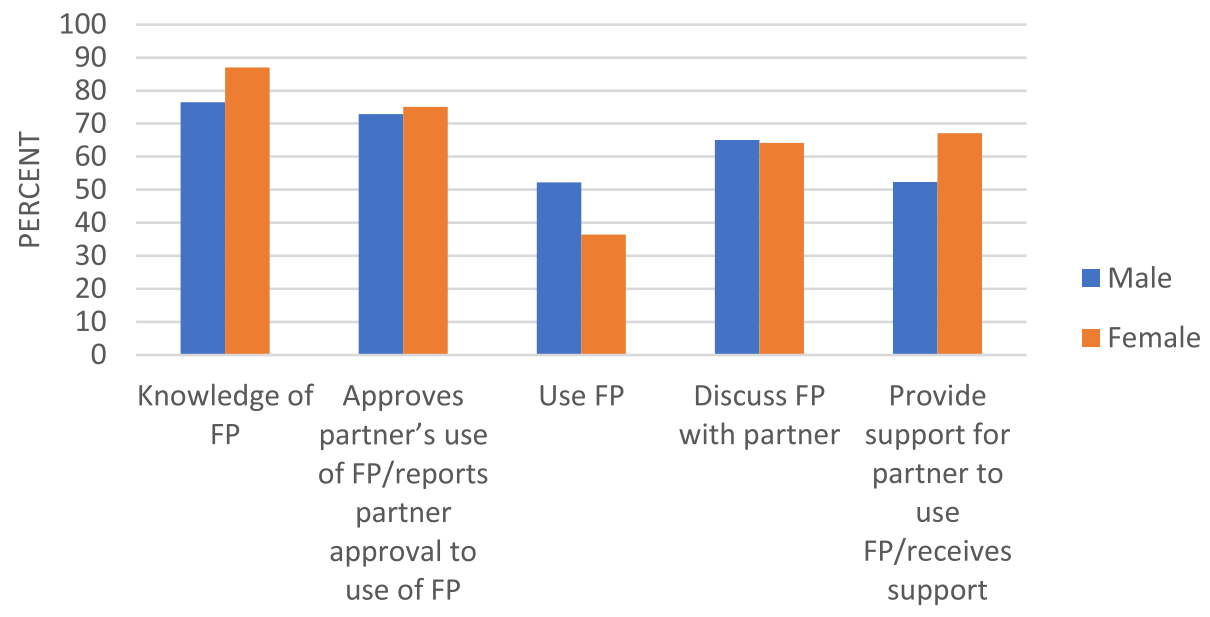

Fig. 1 FP involvement characteristics

population policy development on contraceptive behavior is that men are often not targeted in FP programs [22].

Our study identified several factors associated with men's influence in FP service utilization among their partners. Non-approval of FP methods by men in this study was attributed to perceived risks, side effects, and socio-cultural norms. Focus group discussions with men and women in rural Uganda have come out with similar findings [9]. Contraceptive knowledge and use are shaped by the socio-cultural environment such as personal attitudes and feelings about contraception. In rural settings in low and -middle income countries most men may be unwilling to have their wives adopt FP, which they have little knowledge about. Evidence shows that some men oppose contraceptive use for reasons of tradition and religion which require men to maintain the honor and position of their extended family, village, religious group and social organization [23]. Studies have shown with similar findings in settings in rural northern Ghana $[24,25]$. The complex web of social and cultural factors impedes spousal communication regarding reproductive health issues and that discourages them to take their wives to health clinics to discuss FP issues [22].

Two important factors were identified to be positively associated with men's involvement in FP use in our study; Knowledge on FP and the number of living children male partners had were positively associated with their involvement in FP use. Knowledge about FP will influence acceptance and therefore impact involvement of men in its utilization. Similar studies by $[26,27]$ have found FP knowledge to be positively linked with its 
utilization. Our study additionally revealed that men who had greater than two living children were more likely to be involved in FP service utilization. The number of living children have also been shown to be associated with contraceptive use among women in previous studies [28, 29]; couples with living children tend to use contraceptives space their births or limit the number of children. Several interventions can be used to address barriers in the uptake of FP services in this setting. Family planning programs need to target men at all levels of health promotion and education with their partners to reduce misconceptions about FP methods to increase acceptance [20]. Men's participation is crucial to help reduce misconception about side effects of contraceptive methods [20]. Therefore, FP family programs need to target men at all levels of the service. Their involvement will also lead to women's empowerment to increase effective contraceptive use and continuation to improve better health outcomes in reproductive health [30]. User experiences indicate that text messages provide a novel way to raise awareness, promote behavior change and address myths and socio-cultural norms [31].

\section{Limitations}

This study has some limitations which need to be taken into consideration. The finding of this study cannot be generalized to the entire region of the Upper West region due to the small sample size. Despite the small sample size, views of groups of our respondents which comprised of married partners and those cohabitating, will not differ significantly from the rest of the entire population in the region. Also, this study provides vital insights for policymakers in Ghana and beyond who are working to improve sexual and reproductive health services for men and women. The need for future study to capture the perspectives of men and women on cultural factors influencing PF services for policy.

\section{Conclusions}

Our study demonstrated high knowledge of FP among partners. However, the use of modern contraceptives methods was low due to side effects and socio-cultural norms. Involving men partners in FP programs could give them accurate and complete information on contraceptive methods to help reduce misconception and increase uptake. Reproductive health program designers, policymakers, and population researchers, health professionals need to incorporate the findings into reproductive health programs to help address barriers to improve health outcomes among couples.

\section{Abbreviations}

FP: Family Planning; LMICs: Low- and Middle-Income Countries.

\section{Acknowledgements}

The authors wish to acknowledge all study participants for their cooperation in providing the necessary information and the research assistants for data collection.

\section{Authors' contributions}

SAKK conceived the study and conducted the field work. SAKK and TA designed the study and performed the statistical analysis. ASL drafted the manuscript. SAKK and TA reviewed the manuscript. All authors read and approved the final manuscript".

\section{Funding}

The authors received no funding for this work.

Availability of data and materials

The dataset for this study is available on request from the corresponding author.

\section{Declarations}

Ethics approval and consent to participate

Ethics approval was obtained from the Institutional Review Board of the Community Health Department of the University for Development Studies in Ghana. Informed consent was obtained from the study participants before data collection.

\section{Consent for publication}

All authors read the manuscript and approved it for publication.

\section{Competing interests}

None to declare.

\section{Author details}

${ }^{1}$ Seventh-Day Adventist Hospital, Koforidua, Eastern Region, Ghana. ${ }^{2}$ REJ Institute, Research and ICT Consultancy Services, Tamale, Northern Region, Ghana. ${ }^{3}$ Department of Community Health and Family Medicine, SMHS University for Development Studies, Tamale, Northern Region, Ghana.

Received: 7 April 2021 Accepted: 4 February 2022

Published online: 21 February 2022

References

1. World Health Organization. Contraception: evidence brief. No. WHO/ RHR/19.18. Geneva: World Health Organization; 2019.

2. Ghana Statistical Service (GSS), G.H.S.G., and ICF. Ghana Maternal Health Survey 2017: Key findings. Rockville: GSS, GHS, and ICF; 2018.

3. MacQuarrie K. Unmet need for family planning among young women: levels and trends; 2014.

4. Wulifan JK, et al. A scoping review on determinants of unmet need for family planning among women of reproductive age in low and middle income countries. BMC Womens Health. 2015;16(1):1-15.

5. Demissie TW, Tegegne EM, Nigatu AM. Involvement in family planning service utilization and associated factors among married men at Debre Tabor town, Northwest Ethiopia, 2017. Pan Afr Med J. 2021;38:211.

6. Chola $\mathrm{L}$, et al. Scaling up family planning to reduce maternal and child mortality: the potential costs and benefits of modern contraceptive use in South Africa. PLoS One. 2015;10(6):e0130077.

7. Khan SA, et al. A comparative trial of copper T 380 and cu 375 IUCD. J Ayub Med Coll Abbottabad. 2010;22(3):185-7.

8. Mistik $S$, et al. Married men's opinions and involvement regarding family planning in rural areas. Contraception. 2003;67(2):133-7.

9. Kabagenyi $\mathrm{A}$, et al. Barriers to male involvement in contraceptive uptake and reproductive health services: a qualitative study of men and women's perceptions in two rural districts in Uganda. Reprod Health. 2014;11(1):21.

10. Vouking MZ, Evina CD, Tadenfok CN. Male involvement in family planning decision making in sub-Saharan Africa-what the evidence suggests. Pan Afr Med J. 2014;19:349. 
11. Organization, W.H. Programming for male involvement in reproductive health: Report of the meeting of WHO regional advisers in reproductive health, WHO/PAHO, Washington DC, USA 5-7 September 2001. Geneva: World Health Organization; 2002.

12. GSS, G., Ghana statistical service (GSS), Ghana health service (GHS), and ICF macro. Accra: Ghana Demogr Health Surv, 2009. 2008: p. 79-96.

13. Staveteig, S., Understanding unmet need in Ghana: Results from a followup study to the 2014 Ghana Demographic and Health Survey. 2016: ICF International.

14. Adanu RM, et al. Contraceptive use by women in Accra, Ghana: results from the 2003 Accra Women's health survey. Afr J Reprod Health. 2009;13(1):123-33.

15. Kuganab-Lem RB, Dogudugu R, Kanton L. Birth preparedness and complication readiness: a study of postpartum women in a rural district of Ghana. Public Health Res. 2014;4(6):225-33.

16. Apusigah AA. The gendered politics of farm household production and the shaping of women's livelihoods in northern Ghana. Feminist Africa. 2009;12(12):51-67.

17. Williamson LM, et al. Limits to modern contraceptive use among young women in developing countries: a systematic review of qualitative research. Reprod Health. 2009;6(1):3.

18. Service, G.S. 2010 Population \& Housing Census. Sissala East District: District Analytical Report; 2014.

19. Report, S.E.D.H.D., Resource endowment, investment opportunities and the attainment of MDGs. 2011.

20. Bayray A. Assessment of male involvement in family planning use among men in south eastern zone of Tigray, Ethiopia. Scholarly J Med. 2012;2(2):1-10.

21. Mbizvo MT, Adamchak DJ. Family planning knowledge, attitudes, and practices of men in Zimbabwe. Stud Fam Plan. 1991;22(1):31-8.

22. Shahjahan M, Kabir M. Why males in Bangladesh do not participate in reproductive health: lessons learned from focus group discussions. Int $\mathrm{Q}$ Community Health Educ. 2006;26(1):45-59.

23. Tuloro $T$, et al. The role of men in contraceptive use and fertility preference in Hossana town, southern Ethiopia. Ethiop J Health Dev. 2006;20(3).

24. Apanga PA, Adam MA. Factors influencing the uptake of family planning services in the Talensi District, Ghana. Pan Afr Med J. 2015;20(1):10.

25. Eliason $\mathrm{S}$, et al. Determinants of unintended pregnancies in rural Ghana. BMC Pregnancy Childbirth. 2014;14(1):261.

26. Manortey $\mathrm{S}$. Determinants of male involvement in family planning services: a case study in the Tema Metropolis, Ghana. Open Access Libr J. 2020;7(01):1.

27. Kasa AS, Tarekegn M, Embiale N. Knowledge, attitude and practice towards family planning among reproductive age women in a resource limited settings of Northwest Ethiopia. BMC Res Notes. 2018;11(1):1-6.

28. Haq I, Sakib S, Talukder A. Sociodemographic factors on contraceptive use among ever-married women of reproductive age: evidence from three demographic and health surveys in Bangladesh. Med Sci. 2017;5(4):31.

29. Islam AZ, et al. Prevalence and determinants of contraceptive use among employed and unemployed women in Bangladesh. Int J MCH AIDS. 2016;5(2):92.

30. Kassa M, Abajobir AA, Gedefaw M. Level of male involvement and associated factors in family planning services utilization among married men in Debremarkos town, Northwest Ethiopia. BMC Int Health Hum Rights. 2014;14(1):33.

31. Riley P, et al. Mobiles for quality improvement pilot in Uganda. Bethesda: Abt Associates, Strengthening Health Outcomes through the Private Sector Project; 2011.

\section{Publisher's Note}

Springer Nature remains neutral with regard to jurisdictional claims in published maps and institutional affiliations. 